\title{
Mesotelioma pleuroperitoneal em bovino - relato de caso
}

Tiago da Cunha Peixoto, Vitor Santiago de Carvalho, Múcio Fernando Ferraro de Mendonça, Marcela Próspero Rodrigues Pinto, Thanielle Novaes Fontes, Gabriel Saraiva Diniz Gonçalves, Elainne Maria Beanes da Silva Santos, Juliana d’Almeida Nunes, Roberto Viana Menezes, Karina Medici Madureira

Escola de Medicina Veterinária e Zootecnia, Departamento de Anatomia, Patologia e Clínicas Veterinárias, Universidade Federal da Bahia (UFBA), Salvador, BA, Brasil

*Autor correspondente

e-mail: tcpeixoto@ufba.br

\section{Resumo}

O mesotelioma é uma neoplasia originária das células mesodérmicas, que revestem as cavidades pleural, pericárdica e peritoneal e também a túnica vaginal do testículo. São tumores raros nos animais domésticos e têm sido descritos em bovinos, cães e, com menor frequência, em equinos, suínos e gatos. A etiologia ainda não foi completamente elucidada. Entretanto, em bovinos o mesotelioma pode ser congênito, enquanto no homem existe relação direta entre a inalação crônica de partículas de amianto, e em cães é de ocorrência espontânea. Em julho de 2016, uma vaca Nelore, com sete anos de idade, oriunda do município de Coração de Maria-Bahia, foi atendida no Centro de Desenvolvimento da Pecuária da UFBA. Ao exame físico verificaramse apatia, anorexia, discreta desidratação, dispnéia mista com padrão abdominal, taquicardia, hipofonese cardíaca e resistência a exercícios. Suspeitou-se de retículo pericardite traumática e institui-se um tratamento hidroeletrolítico, assim como antibioticoterapia e antiinflamatórios. Os exames hematológicos não revelaram alterações. 0 animal permaneceu internado por dois dias, havendo agravamento do quadro clínico seguido de óbito. À necropsia, observaram-se cerca de 40 litros de líquido serossanguinolento livre na cavidade abdominal e 25 litros na cavidade torácica, focos de atelectasia pulmonar e múltiplos nódulos em omento, peritônio, fígado, baço, diafragma, pleura e pulmões que variavam de poucos milímetros a $1,5 \times 0,7 \times 0,3 \mathrm{~cm}$ com aspecto arborescente, papiliforme ou em placas irregulares, brancacentas a avermelhadas e friáveis de distribuição aleatória. Fragmentos de diversos órgãos foram colhidos, fixados em formol a $10 \%$ e processados pelos métodos rotineiros de histopatologia. Os cortes histológicos das massas peritoneais, pleurais (pleura parietal), hepáticas superficiais (cápsula de Glisson), diafragmáticas, mesentéricas, pulmonares (pleurais), da superfície esplênica e do omento, corados em hematoxilina-eosina evidenciaram neoplasia mesotelial de crescimento infiltrativo caracterizada pela formação de numerosas 
projeções papilares apoiadas em estroma fibrovascular e revestidas por células cúbicas ou fusiformes, hipercromáticas, moderadamente pleomórficas, com grandes núcleos arredondados a ovóides, algo vesiculares, nucléolos centrais, únicos ou duplos, contendo escasso citoplasma eosinofílico. Em algumas áreas havia formação de massas sólidas constituídas por células neoplásicas arranjadas em formações tubulares. Figuras de mitoses eram relativamente frequentes, sendo algumas atípicas. Adicionalmente, havia múltiplos focos metastáticos em meio ao parênquima pulmonar. Os achados anatomopatológicos e histopatológicos ora relatados foram compatíveis com um quadro de insuficiência respiratória secundária à neoplasia maligna disseminada, a qual comprometeu a função de músculos respiratórios (diafragma), resultando em intenso hidrotórax, atelectasia compressiva, enfisema e trombose pulmonares. A avaliação microscópica das massas neoplásicas confirmou tratar-se de mesotelioma pleuroperitoneal maligno, com disseminação para múltiplos órgãos e tecidos (fígado, diafragma, mesentério, pulmão, baço e omento). O diagnóstico de mesotelioma pleuroperitoneal maligno foi estabelecido com base nos dados clínicoepidemiológicos, necroscópicos, e confirmado pelo exame histopatológico. 